\title{
GESTALT PSYCHOLOGY IN 1962
}

\author{
Wolfgang KÖHLER \\ Dartmouth College, New Hampshire
}

I was recently asked by a friend whether I am satisfied with the present situation in Gestalt psychology. My answer was that Gestalt psychology is surely not quite so active now as it was a number of years ago. I then tried to explain the change as follows.

I am not inclined to believe that factors inherent in the make-up of Gestalt psychology itself are responsible for its temporary loss of vigor. In the past, the School has raised numerous questions which have proved to be highly productive, but have not yet been completely answered. It scems to me just as inviting and urgent a task to find the right answers at the present time as it ever was before. Moreover, when now dealing with problems which have never been investigated by Gestalt psychologists in the early period of their work, I often discover that the most likely solutions of such new problems are closely related to the original statements of the School. Obviously, therefore, it must have been outside factors which have recently retarded further growth, and some such factors are well known. We remember that many leading Gestalt psychologists had to leave Europe for political reasons. Their art of asking basic psychological questions, of giving bold tentative answers, and of inventing corresponding new procedures of investigation could, therefore, be transferred to a new European generation only by the few who remained in the Old Countries. Clearly, their number did not suffice, particularly since, at the time, younger people in these countries were unable to pay much attention to purely cognitive tasks. Hence, even the brilliant work of Michotte and several others did not influence as many students as it would have under normal conditions.

Most of the Gestalt psychologists who had emigrated died before they could transmit to psychologists in their new environments the enthusiasm and the intellectual curiosity which had produced their own discoveries. This task was also made difficult by the fact that, particularly in America, convictions of an entirely different kind had spread among psychologists long before the Europeans arrived, and had become highly resistant to change. I am referring to the theses of what is now called Methodological Behaviorism. Under the circumstances, new problems and scientific suggestions such as those imported by the Gestalt psychologists aroused suspicion rather than interest in members of the American School.

One particular discrepancy between the Behaviorists and the Gestalt psychologists has proved to be decisive. The Behaviorists insist that only such issues deserve to be studied by the psychologist as can be handled with the inductive techniques of natural science. For instance, how does an animal or a human being respond to this or that condition imposed from the outside? Both conditions and responses are mostly simple facts, the nature of which seems to offer no problems. But various questions arise when either the same conditions are given repeatedly, or others substituted, and when now the sub- 
ject's responses change, or do not change. Experiments on "conditioning" in this sense may be varied in many directions. In all cases, exact statistical procedures serve to show whether changed responses are actually brought about by changed functional connections within the subject.

No Gestalt psychologist will deny that, as a matter of principle, such procedures are valuable. At times, results have been admirable. Generally speaking, however, the Behaviorist's work tends to appear to others as fairly monotonous and narrow in scope, particularly when mere details of conditioning are forever explored by patient students. A Gestalt psychologist will, therefore be inclined to tell the Behaviorist that, while exact methods of proof or disproof are to be highly respected, not all Behaviorists seem to be skillful in inventing new questions which can then be answered with such methods. And do not advances in a young discipline depend as much upon productive questions as upon the use of precise techniques of testing?

When, the Gestalt psychologist will therefore ask, do new important questions arise in a science? Unfortunately, while we have strict rules about the quantitative handling of given questions, we have no rules about the way in which such questions are to be discovered. As Plato, the philosopher, once remarked, progress in cognitive matters tends to occur when a thinker is surprised by certain facts. It is such surprises which lead to new questions. And when is a thinker or scientist likely to be surprised? This happens either when a fact is obviously at odds with otherwise generally accepted views, or when, suddenly, a given fact reminds him of apparently similar facts elsewhere. Naturally, helpful surprises of both kinds can occur only if the people involved have information for beyond the area with which they are directly concerned at the time. This many Behaviorists do not seem to realize. They prefer to consider only limited numbers of facts and concepts, and have, therefore, few opportunities for being surprised in that helpful fashion.

That this is the right explanation of the School's rigid and limited program is amply verified by the work of those Behaviorists who have recently become interested in larger areas of research such as, for instance, brain physiology. This extension of the field in which they operate has at once led to entirely new questions, and to answers which make a strong impression on all psychologists. It remains to be seen whether other members of the School are ready to follow this excellent example.

The Gestalt psychologist has never been tempted to regard even the best techniques of testing as substitutes for the art of discovering exciting problems. When valuable evidence can be gained in a simpler fashion, he has not hesitated to make use of the opportunity. Now, the very simplest consideration of directly accessible, that is, phenomenal facts will often surprise an observer who is aware of the context in which these facts must be seen. Inspection of such facts is most reliable in the field of perception. Hence, the early work of the Gestalt psychologists referred to findings in this area. If a Behaviorist should now object, and say that no observation of mere phenomena will ever convince a true scientist, the Gestalt psychologist would have to answer that, invariably, the Behaviorist's own observations occur in his, the Behaviorist's, perceptual field. For here his subject, the experimental conditions and the subject's responses are given to him as perceptual facts. To be sure, these facts do not interest him as contents of his own percep- 
tual world; he merely uses them as evidence concerning the physical behavior of the subject. But, surely, he would not make use of them for this purpose if he did not believe that they can be trusted. Consequently, the Gestalt psychologist, too, is justified in believing that, often, perceptual facts are sturdy and reliable objects of observation. But then, he will conclude, I must also be allowed to study them for their own. sake.

Although Gestalt psychologists have worked on problems in various parts of our science, in the following brief remarks I will emphasize their contributions to our knowledge of perception for this reason: It was just a few puzzling facts within this field which made the School ask its first relevant questions; but, almost immediately, the same questions proved to be essential also in other fields, such as learning, thinking, and even neurophysiology.

I will now enumerate achievements of the School which are generally known, but have seldom been regarded as intimately related. The development began when the full importance of a problem in perception was first recognized by Wertheimer. How does it happen that our visual fields exhibit those molar segregated units which we call "objects"? The fact that they do appeared surprising because, from the point of view of the physicists, the ophthalmologists and the neurophysiologists of the time, "organization" in this sense could surely not be expected. According to these scientists, local optic stimuli act on local cells of the retina, and local nerve impulses which thus originate travel in separate fibers toward the brain. If such atomic events completely determined the nature of visual fields, these fields would have to be mere mosaics of corresponding local facts. But, for the most part, visual fields do exhibit that molar order, the segregation of specific unitary entities. Hence the Gestalt psychologist's surprise. He soon realized that organization in this sense can only be established by interactions among the local effects of stimulation, both at the retinal and at higher levels of the nervous system. Actually, some interactions in the visual system are now known to be mediated by impulses which travel in transverse nerve fibers; but interactions of this kind can clearly not be responsible for the emergence of segregated molar objects. Thus, Gestalt psychologists began to suspect that nerve impulses are not the only processes that occur in neural tissues. In fact, it soon became probable that, where neural excitations of one kind are surrounded by excitations of another kind, steady currents will flow through the surrounded area, and then return to this area through its environment. This assumption was greatly encouraged when, just at this time, physiologists first registered direct currents from activated regions in the nervous systems of some animals. Soon afterwards, our investigation of figural after-effects, which amplified Gibson's earlier observations, further supported the Gestalt psychologist's main assumption; for, steady currents are known to affect neural tissue in a way which greatly resembles the perceptual obstruction called "satiation". In spite of the untiring efforts of many psychologists in Japan, some figural after-effects have not yet been explained in such, or any other, terms; but, then, not all consequences of our theory have so far been consistently developed. At any rate, it now seemed advisable to test the basic thesis of this theory by taking records of cortical processes when subjects are confronted with visual objects or other perceptual facts. Many tests of this kind have been done in man and in animals. Results clearly indicate that under these conditions steady 
currents spread not only in the lower neural centers previously investigated by physiologists but also in cortical areas.

Surely, this has been a rapid development. Thus, the Gestalt psychologist's tendency to pay attention to any evidence which promises to raise new problems has been justified. In my present remarks, only one line in the history of Gestalt psychology has been followed; but, if I had considered other developments in this history, our final impression would probably have been the same.

I do feel that, if now Gestalt psychology seems to be less active, this fact cannot be caused by defects inherent in the School's basic tenets. Hence, I repeat my own explanation: we merely have not been able to convince a younger generation that the Gestalt psychologist's work is worth their support. And yet, so much of this work remains to be done-precisely because, in the past, Gestalt psychology has grown almost too fast. At some points, even important questions have not yet been asked, certain statements of the School are surely in need of further clarification, and critics may also discover that, occasionally, a Gestalt psychologist's conclusions have been mistaken. All this can only strengthen my wish that, in the near future, our interests will also become those of others, who can then continue and improve what we have sofar done.

MS. received I 7 '63

Wolfgang Köhler (1887-) Post office Box 32, Lebanon, New Hampshire, U.S.A. 